\title{
Quantification of Enterocytozoon hepatopenaei (EHP) in Penaeid Shrimps from Southeast Asia and Latin America Using TaqMan Probe-Based Quantitative PCR
}

\author{
Patharapol Piamsomboon ${ }^{1,+} \oplus$, Seong-Kyoon Choi ${ }^{2,3,+}$, Bambang Hanggono $4 \oplus$, \\ Yani Lestari Nuraini ${ }^{4}$, Fatma Wati ${ }^{4}$, Kathy F. J. Tang ${ }^{5}$, Song Park ${ }^{2}$, Dongmi Kwak ${ }^{6}$, \\ Man Hee Rhee ${ }^{6}{ }^{\circ}$, Jee Eun Han ${ }^{6, *}$ and Ji Hyung Kim ${ }^{7, *}$ \\ 1 Department of Veterinary Medicine, Faculty of Veterinary Science, Chulalongkorn University, \\ Bangkok 10330, Thailand; patharapol.p@chula.ac.th \\ 2 Core Protein Resources Center, DGIST, Daegu 42988, Korea; cskbest@dgist.ac.kr (S.-K.C.); \\ cristaling@dgist.ac.kr (S.P.) \\ 3 Division of Biotechnology, DGIST, Daegu 42988, Korea \\ 4 Fish Health and Environmental Laboratory, Brackishwater Aquaculture Development Center, \\ Situbondo 68351, Indonesia; bambanghanggono@gmail.com (B.H.); yani_bbaps@yahoo.co.id (Y.L.N.); \\ fatmawatiaziz06@gmail.com (F.W.) \\ 5 Yellow Sea Fisheries Research Institute, Chinese Academy of Fishery Sciences, Qingdao 266071, China; \\ ktangnelson@gmail.com \\ 6 College of Veterinary Medicine, Kyungpook National University, Daegu 41566, Korea; \\ dmkwak@knu.ac.kr (D.K.); rheemh@knu.ac.kr (M.H.R.) \\ 7 Infectious Disease Research Center, Korea Research Institute of Bioscience and Biotechnology, Daejeon 34141, \\ Korea \\ * Correspondence: jehan@knu.ac.kr (J.E.H.); kzh81@kribb.re.kr (J.H.K.) \\ + These authors equally contributed in this work.
}

Received: 25 October 2019; Accepted: 11 November 2019; Published: 12 November 2019

\begin{abstract}
We developed a qPCR assay based on the $\beta$-tubulin gene sequence for the shrimp microsporidian parasite Enterocytozoon hepatopenaei (EHP). This assay reacted with the hepatopancreas (HP) of EHP-infected shrimps, and the highest copy numbers were found in HP and feces samples from Southeast Asian countries $\left(10^{6}-10^{8}\right.$ copies $\left.\mathrm{mg}^{-1}\right)$, while HP samples from Latin America, Artemia, and EHP-contaminated water showed lower amounts $\left(10^{1}-10^{3}\right.$ copies $\mathrm{mg}^{-1}$ or $\mathrm{mL}^{-1}$ of water). No false positive was found with the normal shrimp genome, live feeds, or other parasitic diseases. This tool will facilitate the management of EHP infection in shrimp farms.
\end{abstract}

Keywords: Enterocytozoon hepatopenaei; qPCR; microsporidian; shrimp parasite

The microsporidian Enterocytozoon hepatopenaei (EHP), an intracellular spore-forming parasite, is a major threat to the commercial shrimp industry. The infection is specific to the tubular epithelial cells of the hepatopancreas (HP) of shrimps. Shrimps in an advanced stage of EHP infection show signs of lethargy, reduced feed intake, soft shells, and an empty midgut [1]. This parasite was first recorded in Thailand in 2003, as an unknown microsporidian species infecting the HP of the black tiger shrimp Penaeus monodon [2]. It was characterized in 2009 as a new member of the genus Enterocytozoon, in the family Enterocytozoonidae [3]. Subsequently, it has been found in the more economically important Pacific white shrimp P. vannamei cultured in various Asian countries, including China, Thailand, Indonesia, Malaysia, Vietnam, and India [4-7]. Recently, EHP has also been reported in Venezuela, South America [8]. 
Severe EHP infections have become common in ponds, and result in substantial economic losses to shrimp producers, since they are associated with inhibited growth in cultured shrimps [1]. EHP infections have also been reported in normal shrimp reared in earthen ponds [5]. Since growth inhibition may depend upon the degree of EHP infection, a means of convenient quantitation of the amount of EHP in infected individuals is needed.

Several EHP diagnostic methods based on SSU rRNA are available, including PCR, in situ hybridization, and loop-mediated isothermal amplification assays [1-4,9]. Moreover, the qPCR assay has been developed to determine the number of EHP, which is useful for the study of disease progress and quantification of the EHP [10]. However, SSU rRNA sequences are highly conserved among microsporidia, so this may generate false positives in non-shrimp samples $[11,12]$. On the contrary, the $\beta$-tubulin gene sequence has sufficient variability for molecular diagnosis at the species level [13]. For more specific EHP quantification, we developed a qPCR assay based on the $\beta$-tubulin gene.

In this study, we developed a qPCR assay based on the $\beta$-tubulin gene sequence for EHP-specific quantification. This assay was then applied to examine shrimp and feces samples collected from various countries to quantify the level of EHP present. The method was also applicable for screening live shrimp feeds and water samples.

The primers and TaqMan probe were designed based on the $\beta$-tubulin gene of the EHP genome (GenBank no. KY593130), using Primer Express v. 3.0 software (Life Technologies). The DNA fragment (84-bp) was amplified using the forward primer (EHP-bTub-F2: 5'-GATTTGAGAAAATTGG CGGTTAA-3') and the reverse primer (EHP-bTub-R2: $5^{\prime}$-TTCTGAACACAGAGGCGCATA- $3^{\prime}$ ), while the TaqMan probe (5'-TGATTCCATTTCCACGACTGCACTTTTTC-3') was synthesized and labeled with 6-carboxyfluorescein (FAM) on the $5^{\prime}$ end and $N, N, N^{\prime}, N^{\prime}$-tetramethyl-6-carboxyrhododamine (TAMRA) on the $3^{\prime}$ end. The qPCR assay was performed by combining $1 \mu \mathrm{L}$ extracted DNA and a qPCR mixture containing 2.5 $\mu \mathrm{l}$ TaqMan Faster Universal PCR Master Mix (Life Technologies), $0.3 \mu \mathrm{M}$ of each primer, and $0.1 \mu \mathrm{M}$ TaqMan probe for a final volume of $10 \mu \mathrm{l}$. Amplification was performed by thermal cycling for $20 \mathrm{~s}$ at $95^{\circ} \mathrm{C}$ followed by 40 cycles of $3 \mathrm{~s}$ at $95^{\circ} \mathrm{C}$ and $30 \mathrm{~s}$ at $60^{\circ} \mathrm{C}$. Amplification and data analysis were performed using a StepOnePlus PCR system (Life Technologies).

A positive control was generated using a sequence of the $\beta$-tubulin gene from the EHP isolate 16-505/HP (Table 1) and cloned into the pGEM-T-Easy vector (Promega). By sequencing analysis, four clones from the isolate resulted in only one allele ( $100 \%$ identity), indicating the $\beta$-tubulin gene is a single copy gene in the EHP genome. The plasmid was designated pEHP-tubB-2 (3885-bp) and the concentration was determined by measuring $\mathrm{OD}_{260 \mathrm{~nm}}\left(2.38 \times 10^{8}\right.$ copies per $1 \mathrm{ng}$ of DNA). For a standard curve, the purified pEHP-tubB-2 plasmid was used, and the sensitivity was determined by preparing 10-fold dilutions. A standard curve presenting concentrations from $10^{2}-10^{8}$ copies $\mu \mathrm{L}^{-1}$ is shown in Supplementary Figure S1. The specificity of the qPCR assay was evaluated using qPCR on DNA from the shrimp parasites Perezia sp. microsporidium [14], Paramoeba sp. amoeba [15], and EHP microsporidium as a positive control [6]. The results confirm that the primers and probe from the $\beta$-tubulin gene sequence are specific to EHP, showing no reaction to another shrimp parasites. In addition, DNA from different shrimp species and live shrimp feed were tested to ensure that the primers did not cause false positives (Table 1). 
Table 1. Samples used for testing the specificity of the qPCR assay.

\begin{tabular}{ccc}
\hline Sample & Number of Samples & Number of Positive Samples \\
\hline Pathogen-free P. vannamei & 3 & 0 \\
P. monodon & 3 & 0 \\
P. indicus & 3 & 0 \\
P. stylirostris & 2 & 0 \\
P. aztecus & 2 & 0 \\
Macrobrachium rosenbergii & 2 & 0 \\
Crabs (unknown species) & 3 & 0 \\
Polychaetes & 4 & 0 \\
Artemia & 3 & 0 \\
Plankton & 1 & 0 \\
P. vannamei with Paramoeba sp. infection & 1 & 0 \\
P. monodon with Perezia sp. infection & 1 & 0 \\
P. vannamei (HP) with EHP infection & 77 & 77 \\
Feces with EHP infection & 4 & 4 \\
Artemia with EHP infection & 4 & 4 \\
Water with EHP infection & 1 & 1 \\
\hline
\end{tabular}

To evaluate practical use, a total of 86 samples were collected from a population of EHP-affected P. vannamei (Table 2). These samples included $14 \mathrm{HP}$ and three fecal samples from Thailand, $23 \mathrm{HP}$ samples from Vietnam, $36 \mathrm{HP}$ and one fecal sample from Indonesia, four HP samples from Venezuela, four Artemia biomass samples, and one water sample. For DNA extraction, feces were collected by siphoning onto a $500 \mu \mathrm{m}$ mesh screen, and the water sample was concentrated (1:100) using a Microsep Advance Centrifugal Device (PALL Corporation). Approximately $30 \mathrm{mg}$ of HP, feces, and artemia samples and $300 \mu \mathrm{L}$ of water samples were used for DNA extraction using QIAamp tissue kit (Qiagen). After DNA extraction, the concentration of DNA was measured by a spectrophotometer (BioPhotometer, Eppendorf). The EHP copy number was highest in the HP samples from Indonesia, with a range between $8.0 \times 10^{3}-1.4 \times 10^{8}$ copies mg $^{-1}$, followed by those from Thailand $\left(2.5 \times 10^{2}-9.1\right.$ $\times 10^{7}$ copies $\left.\mathrm{mg}^{-1}\right)$ and Vietnam $\left(1.9 \times 10^{3}-4.8 \times 10^{7}\right.$ copies $\left.\mathrm{mg}^{-1}\right)$. In contrast to the SE Asian samples, HP samples from Latin America presented a relatively low EHP quantity, with copy numbers between $2.1 \times 10^{1}-1.3 \times 10^{2}$ copies $\mathrm{mg}^{-1}$. In the feces sample, $10^{6}-1.7 \times 10^{7}$ copies $\mathrm{mg}^{-1}$ were found, while Artemia samples contained EHP DNA at $4.3 \times 10^{3}-2.8 \times 10^{5}$ copies $\mathrm{mg}^{-1}$. Finally, EHP was detected in the water samples at $1.7 \times 10^{3}$ copies per $\mathrm{mL}^{-1}$.

All samples tested in this study came from shrimps exhibiting slow growth in farms from SE Asia and Latin America, and from contaminated Artemia. This indicates good applicability of the qPCR assay regardless of the source of EHP and their host species. For the Artemia samples, substantial amounts of EHP (as DNA copies) were detected. Live shrimp feeds, including polychaetes, squids, and Artemia biomass, have been suspected to be carriers for EHP, so EHP quantification by qPCR in live shrimp feeds can be used as a tool to aid in disease prevention in broodstock populations. Using qPCR, we also confirmed that feces contained high numbers of EHP copies, indicating that this may act as an important source of infection in ponds. In penaeid shrimps, EHP multiplies rapidly in the HP tubule epithelium cells, and EHP spores are released into the digestive system, causing white feces in ponds [6].

In conclusion, EHP infection is notorious in farmed shrimp ponds, and such EHP infections are likely to continue to be prevalent. The situation requires careful monitoring of EHP levels in shrimps and their feed using a highly specific diagnostic method. In addition, quantification of EHP in live feeds, pond environments, or feces becomes more important for EHP management. This study describes a new quantification method for EHP based on the $\beta$-tubulin gene, applicable in EHP management in shrimp farming. 
Table 2. Sample types tested and quantification of Enterocytozoon hepatopenaei (EHP) by qPCR.

\begin{tabular}{|c|c|c|c|c|c|}
\hline Case No. & Origin & Year & No. of Samples & Sample Types & Copy Number mg ${ }^{-1}$ \\
\hline $14-435 / 1$ & Thailand & 2014 & 1 & Feces & $1.0 \times 10^{6}$ \\
\hline $15-220$ & Thailand & 2015 & 2 & Feces & $2.5 \times 10^{3}, 1.2 \times 10^{6}$ \\
\hline 16-505/HP & Thailand & 2016 & 14 & HP & $\begin{array}{l}2.5 \times 10^{2}, 4.4 \times 10^{2}, 1.2 \times 10^{3}, 1.2 \times 10^{3}, 3.4 \times 10^{3}, 4.1 \times 10^{3}, 5.4 \times 10^{4}, \\
5.2 \times 10^{5}, 4.8 \times 10^{6}, 7.9 \times 10^{6}, 9.9 \times 10^{6}, 2.2 \times 10^{7}, 3.4 \times 10^{7}, 9.1 \times 10^{7} \\
1.9 \times 10^{3}, 3.3 \times 10^{4}, 1.0 \times 10^{5}, 1.6 \times 10^{5}, 2.8 \times 10^{5}, 2.9 \times 10^{5}, 3.1 \times 10^{5},\end{array}$ \\
\hline $14-480$ & Vietnam & 2014 & 23 & $\mathrm{HP}$ & $\begin{array}{c}3.4 \times 10^{5}, 3.4 \times 10^{5}, 6.6 \times 10^{5}, 1.4 \times 10^{6}, 1.8 \times 10^{6}, 2.1 \times 10^{6}, 2.3 \times 10^{6} \\
2.4 \times 10^{6}, 3.0 \times 10^{6}, 3.7 \times 10^{6}, 4.0 \times 10^{6}, 4.1 \times 10^{6}, 4.4 \times 10^{6}, 6.1 \times 10^{6}, \\
1.7 \times 10^{7}, 4.8 \times 10^{7}\end{array}$ \\
\hline $16-273 / F$ & Indonesia & 2016 & 1 & Feces & $6.9 \times 10^{7}$ \\
\hline $16-273 / \mathrm{A}$ & Indonesia & 2016 & 1 & $\mathrm{HP}$ & $3.0 \times 10^{6}$ \\
\hline $16-273 / \mathrm{C}$ & Indonesia & 2016 & 10 & HP & $\begin{array}{c}1.0 \times 10^{6}, 1.6 \times 10^{6}, 3.9 \times 10^{6}, 4.4 \times 10^{6}, 5.3 \times 10^{6}, 5.5 \times 10^{6}, 2.6 \times 10^{7}, \\
4.3 \times 10^{7}, 4.5 \times 10^{7}, 7.9 \times 10^{7}\end{array}$ \\
\hline $16-597$ & Indonesia & 2016 & 5 & $\mathrm{HP}$ & $\begin{aligned} 8.0 \times 10^{3}, 6.9 \times 10^{5}, 2.5 \times 10^{6}, 4.3 \times 10^{6}, 9.1 \times 10^{6} \\
5.0 \times 10^{4}, 2.0 \times 10^{5}, 4.0 \times 10^{5}, 1.6 \times 10^{7}, 1.8 \times 10^{7}, 2.4 \times 10^{7}, 2.5 \times 10^{7},\end{aligned}$ \\
\hline 16-663/A & Indonesia & 2016 & 20 & $\mathrm{HP}$ & $\begin{array}{c}2.6 \times 10^{7}, 2.7 \times 10^{7}, 3.2 \times 10^{7}, 3.2 \times 10^{7}, 4.3 \times 10^{7}, 4.5 \times 10^{7}, 5.1 \times 10^{7}, \\
5.2 \times 10^{7}, 5.5 \times 10^{7}, 9.0 \times 10^{7}, 9.6 \times 10^{7}, 1.0 \times 10^{8}, 1.4 \times 10^{8}\end{array}$ \\
\hline $16-681$ & Venezuela & 2016 & 4 & $\mathrm{HP}$ & $2.1 \times 10^{1}, 4.5 \times 10^{1}, 6.2 \times 10^{1}, 1.3 \times 10^{2}$ \\
\hline $14-428$ & Commercial & 2014 & 1 & Artemia & $4.4 \times 10^{3}$ \\
\hline $14-350$ & Commercial & 2015 & 1 & Artemia & $4.3 \times 10^{3}$ \\
\hline $15 / 025$ & Commercial & 2015 & 2 & Artemia & $1.2 \times 10^{5}, 2.8 \times 10^{5}$ \\
\hline $14-435 / 2$ & Laboratory & 2017 & 1 & Water & $1.7 \times 10^{3}\left(\right.$ Copy no. $\left.\mathrm{mL}^{-1}\right)$ \\
\hline
\end{tabular}


Supplementary Materials: The following are available online at http://www.mdpi.com/2076-0817/8/4/233/s1, Figure S1: Standard curve of EHP qPCR, based on a standard curve of the copy number of $\beta$-tubulin gene versus the qPCR Ct (threshold cycle). Purified pEHP-tubB-2 plasmid was serially diluted from 108 to 102 copies per reaction and used as a template in the qPCR. The resulting $\mathrm{Ct}$ values are plotted against the logarithm of their respective copy number; Figure S2: Amplification plots of Enterocytozoon hepatopenaei (EHP) samples were detected by qPCR (with standards). DNAs were prepared from hepatopancreas (HP), feces, artemia, and water.

Author Contributions: Conceptualization, P.P. and J.E.H.; data curation, S.-K.C., B.H., Y.L.N., and F.W.; formal analysis, B.H., Y.L.N., and F.W.; funding acquisition, J.E.H. and J.H.K.; investigation, S.P., D.K., and M.H.R.; methodology, P.P., S.-K.C., and J.E.H.; project administration, J.E.H.; resources, K.F.J.T. and J.E.H.; supervision, J.E.H.; writing-original draft, J.E.H. and J.H.K.; and writing—review and editing, J.E.H. and J.H.K.

Funding: This research was supported by Kyungpook National University Research Fund, 2018.

Conflicts of Interest: The authors declare that they have no conflict of interest.

\section{References}

1. Tang, K.F.; Pantoja, C.R.; Redman, R.M.; Han, J.E.; Tran, L.H.; Lightner, D.V. Development of in situ hybridization and PCR assays for the detection of Enterocytozoon hepatopenaei (EHP), a microsporidian parasite infecting penaeid shrimp. J. Invertebr. Pathol. 2015, 130, 37-41. [CrossRef] [PubMed]

2. Chayaburakul, K.; Nash, G.; Pratanpipat, P.; Sriurairatana, S.; Withyachumnarnkul, B. Multiple pathogens found in growth-retarded black tiger shrimp Penaeus monodon cultivated in Thailand. Dis. Aquat. Organ. 2004, 60, 89-96. [CrossRef] [PubMed]

3. Tourtip, S.; Wongtripop, S.; Stentiford, G.D.; Bateman, K.S.; Sriurairatana, S.; Chavadej, J.; Sritunyalucksana, K.; Withyachumnarnkul, B. Enterocytozoon hepatopenaei sp. nov. (Microsporida: Enterocytozoonidae), a parasite of the black tiger shrimp Penaeus monodon (Decapoda: Penaeidae): Fine structure and phylogenetic relationships. J. Invertebr. Pathol. 2009, 102, 21-29. [CrossRef] [PubMed]

4. Tangprasittipap, A.; Srisala, J.; Chouwdee, S.; Somboon, M.; Chuchird, N.; Limsuwan, C.; Srisuvan, T.; Flegel, T.W.; Sritunyalucksana, K. The microsporidian Enterocytozoon hepatopenaei is not the cause of white feces syndrome in whiteleg shrimp Penaeus (Litopenaeus) vannamei. BMC. Vet. Res. 2013, 9, 139. [CrossRef] [PubMed]

5. Rajendran, K.; Shivam, S.; Praveena, P.E.; Rajan, J.J.S.; Kumar, T.S.; Avunje, S.; Jagadeesana, V.; Prasad Babua, S.V.A.N.V.; Pandea, A.; Krishnana, N.; et al. Emergence of Enterocytozoon hepatopenaei (EHP) in farmed Penaeus (Litopenaeus) vannamei in India. Aquaculture 2016, 454, 272-280. [CrossRef]

6. Tang, K.F.; Han, J.E.; Aranguren, L.F.; White-Noble, B.; Schmidt, M.M.; Piamsomboon, P.; Risdiana, E.; Hanggono, B. Dense populations of the microsporidian Enterocytozoon hepatopenaei (EHP) in feces of Penaeus vannamei exhibiting white feces syndrome and pathways of their transmission to healthy shrimp. J. Invertebr. Pathol. 2016, 140, 1-7. [CrossRef] [PubMed]

7. Aranguren, L.F.; Han, J.E.; Tang, K.F. Enterocytozoon hepatopenaei (EHP) is a risk factor for acute hepatopancreatic necrosis disease (AHPND) and septic hepatopancreatic necrosis (SHPN) in the Pacific white shrimp Penaeus vannamei. Aquaculture 2017, 471, 37-42. [CrossRef]

8. Tang, K.F.; Aranguren, L.F.; Piamsomboon, P.; Han, J.E.; Maskaykina, I.Y.; Schmidt, M.M. Detection of the microsporidian Enterocytozoon hepatopenaei (EHP) and Taura syndrome virus in Penaeus vannamei cultured in Venezuela. Aquaculture 2017, 480, 17-21. [CrossRef]

9. Suebsing, R.; Prombun, P.; Srisala, J.; Kiatpathomchai, W. Loop-mediated isothermal amplification combined with colorimetric nanogold for detection of the microsporidian Enterocytozoon hepatopenaei in penaeid shrimp. J. Appl. Microbiol. 2013, 114, 1254-1263. [CrossRef] [PubMed]

10. Liu, Y.M.; Qiu, L.; Sheng, A.Z.; Wan, X.Y.; Cheng, D.Y.; Huang, J. Quantitative detection method of Enterocytozoon hepatopenaei using TaqMan probe real-time PCR. J. Invertebr. Pathol. 2018, 151, 191-196. [CrossRef] [PubMed]

11. Jaroenlak, P.; Sanguanrut, P.; Williams, B.A.; Stentiford, G.D.; Flegel, T.W.; Sritunyalucksana, K.; Itsathitphaisarn, $\mathrm{O}$. A nested PCR assay to avoid false positive detection of the microsporidian Enterocytozoon hepatopenaei (EHP) in environmental samples in shrimp farms. PLoS ONE 2016, 11, e0166320. [CrossRef] [PubMed]

12. Stentiford, G.D.; Feist, S.W.; Stone, D.M.; Bateman, K.S.; Dunn, A.M. Microsporidia: Diverse, dynamic, and emergent pathogens in aquatic systems. Trends Parasitol. 2013, 29, 567-578. [CrossRef] [PubMed] 
13. Han, J.E.; Tang, K.F.; Kim, J.H. The use of beta-tubulin gene for phylogenetic analysis of the microsporidian parasite Enterocytozoon hepatopenaei (EHP) and in the development of a nested PCR as its diagnostic tool. Aquaculture 2018, 495, 899-902. [CrossRef]

14. Han, J.E.; Tang, K.F.; Pantoja, C.R.; Lightner, D.V.; Redman, R.M.; Le Groumellec, M. Detection of a new microsporidium Perezia sp. in shrimps Penaeus monodon and P. indicus by histopathology, in situ hybridization and PCR. Dis. Aquat. Organ. 2017, 120, 165-171. [CrossRef] [PubMed]

15. Han, J.E. Detection of the amoebic parasite (order Dactylopodida) in cultured Pacific white shrimp (Litopenaeus vannamei). Aquaculture 2019, 507, 246-250. [CrossRef]

(C) 2019 by the authors. Licensee MDPI, Basel, Switzerland. This article is an open access article distributed under the terms and conditions of the Creative Commons Attribution (CC BY) license (http://creativecommons.org/licenses/by/4.0/). 